\title{
Respostas do legislativo baiano à COVID-19: um retrato panorâmico dos primeiros meses de 2020
}

\author{
Responses from the Bahia's legislature to COVID-19: a panoramic portrait of the first months of
} 2020

Respuestas de la legislatura baiana al COVID-19: un retrato panorámico de los primeros meses de 2020

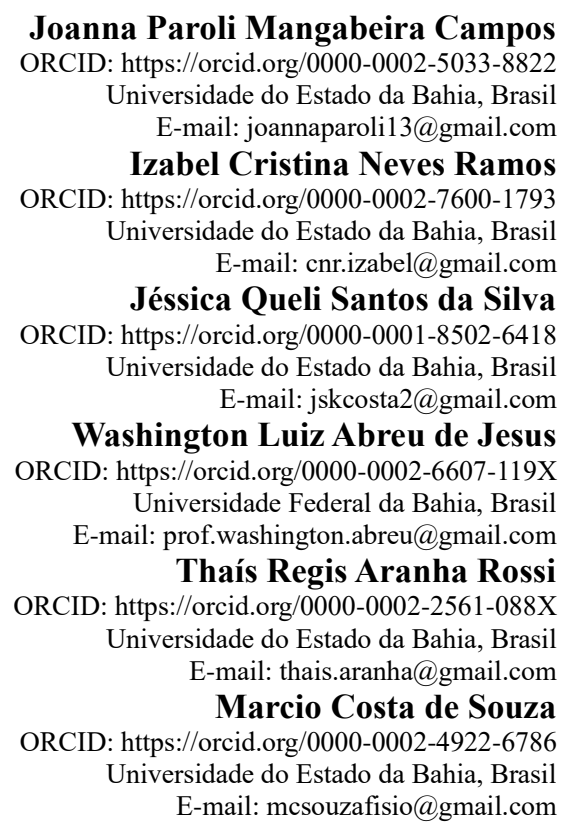

\section{Resumo}

Objetivo: Analisar as respostas iniciais do parlamento baiano no enfrentamento à pandemia da COVID-19. Metodologia: Estudo exploratório e descritivo, realizado através de pesquisa documental, a partir do acesso a informações públicas disponíveis no sítio eletrônico da Assembleia Legislativa da Bahia. Foram investigadas 20 atas de sessões plenárias virtuais, bem como 374 proposições legislativas referentes à COVID-19. O período de análise foi de março a junho de 2020, o qual corresponde ao início do surto da COVID-19 no Brasil e antecede ao primeiro pico de casos na Bahia. Elaborou-se uma matriz de análise, a partir das variáveis: data de entrada, proposição, autor, partido/bancada, medida, tomada de posição, tramitação. Resultados: Apenas 3 categorias de proposições foram aprovadas: as declaratórias de calamidade pública; as que estabeleceram orientações/medidas/ mecanismos de gestão; e as de finalidade econômica/fiscal, sugerindo esforço no preparo da atuação da máquina pública para o combate à pandemia. Dentre as leis sancionadas, citam-se: amplo protagonismo do executivo; tempo célere de tramitação das matérias. Destacam-se políticas de proteção social, com transferência de renda; combate às fake news; reforço às recomendações da OMS. Considerações finais: O regime virtual teve como um dos seus efeitos a redução da participação popular no parlamento e o distanciamento dos agentes políticos com seu eleitorado. Recomendaram-se algumas ações, como a atualização adequada dos dados públicos, o fortalecimento das instâncias formais do parlamento e o monitoramento permanente dos legislativos estaduais.

Palavras-chave: Poder Legislativo; Política Pública; COVID-19.

\section{Abstract}

Objective: To analyze the initial responses of the Bahia's parliament in confronting the COVID-19 pandemic. Methodology: Exploratory and descriptive study, carried out through documentary research, from access to public information available on the website of the Legislative Assembly of Bahia. Twenty minutes of virtual plenary sessions were investigated, as well as 374 legislative proposals referring to COVID-19. The period of analysis was from March 
to June 2020, which corresponds to the beginning of COVID-19 in Brazil and precedes the first peak of cases in Bahia. An analysis matrix was elaborated, based on the variables: date of entry, proposal, author, party / bench, measure, position taken, status of processing. Results: From the point of view of the decision-making process, it was not possible to change independently with the transposition from physical to virtual arena, in addition to adjustments of an organizational nature. Only 3 categories of proposals were approved: the declarations of public calamity; how they established guidelines/measures/management mechanisms; and as practical / fiscal, suggesting an effort to prepare the public machine to fight the pandemic. Among the sanctioned laws, it was found: broad role of the executive; quick processing time of matters; the predilection for social protection policies, with income transfer; effort in combating false news; reinforcement of the WHO recommendations. Finnish considerations: One of the effects of the virtual regime was the reduction of popular participation in parliament and the distance between political agents and their electorate. Some actions were recommended, such as the updating of public data, the strengthening of formal parliaments and the permanent monitoring of state legislatures.

Keywords: Legislative Power; Public Policy; COVID-19.

\section{Resumen}

Objetivo: Analizar las respuestas iniciales del parlamento bahiano ante la pandemia de COVID-19. Metodología: Estudio exploratorio y descriptivo, realizado a través de la investigación documental, desde el acceso a la información pública disponible en el sitio web de la Asamblea Legislativa de Bahía. Se investigaron veinte minutos de plenarias virtuales, así como 374 propuestas legislativas referentes al COVID-19. El período de análisis fue de marzo a junio de 2020, que corresponde al inicio del brote de COVID-19 en Brasil y precede al primer pico de casos en Bahía. Se elaboró una matriz de análisis a partir de las variables: fecha de ingreso, proposición, autor, partido / banquillo, medida, postura tomada, trámite. Resultados: No fue posible demostrar cambios significativos en el proceso de toma de decisiones con la transposición del ámbito físico al virtual, además de los ajustes organizativos. Solo se aprobaron 3 categorías de propuestas: las declaraciones de calamidad pública; los que establecieron lineamientos / medidas / mecanismos de gestión; y aquellos con propósito económico / fiscal, sugiriendo un esfuerzo para preparar el desempeño del sector público para combatir la pandemia. Entre las leyes sancionadas, se encontró: amplio rol del ejecutivo; tiempo de procesamiento rápido de asuntos; la predilección por las políticas de protección social, con transferencia de ingresos; esfuerzo en la lucha contra las noticias falsas; fortalecer las recomendaciones de la OMS. Consideraciones finales: El régimen virtual tuvo el efecto de reducir la participación popular en el parlamento y distanciar a los agentes políticos de su electorado. Se recomendaron algunas acciones, como la adecuada actualización de los datos públicos, el fortalecimiento de las instancias formales y el seguimiento permanente de las legislaturas.

Palabras clave: Poder Legislativo. Política pública. COVID-19.

\section{Introdução}

A Organização Mundial da Saúde (OMS) declarou como pandemia, em 11 de março de 2020, o surto da doença causada pelo novo coronavírus (COVID-19). Até o final do mês de junho de 2021, foram registrados cerca de 177 milhões de casos em todo o mundo, com mais de 3 milhões e 800 mil mortes (PAHO, 2021). No Brasil, somam-se aproximadamente 17 milhões e 600 mil casos, com mais de 500 mil mortes, sendo o segundo país com maior número absoluto de vítimas fatais e representando 33\% do total mundial de mortes diárias pela COVID-19 (WHO, 2021).

A fragilidade da resposta brasileira no combate ao coronavírus escancara seus problemas agudos e crônicos. Liderada pela extrema direita, vem sendo instituída uma agenda de austeridade físcal e de redução do papel do Estado na economia, com repercussão brutal para o aumento das iniquidades sociais (Almeida-Filho, 2021; Guimarães, 2000; Souza \& Souza, 2020). Ademais, o contexto que antecede a chegada da pandemia é de franco desmonte do Sistema Único de Saúde (SUS), a partir de diversas medidas que culminaram em seu desfinanciamento e desregulação, atingindo diretamente a Atenção Básica e diminuindo a capacidade de resposta do sistema (Observatório de Análise Política em Saúde, 2020).

Salienta-se a ausência de resposta coordenada pelo governo federal e discurso que poderia representar a oposição entre vida e economia (Caponi, 2020). Após meses de COVID-19, o executivo federal não tinha qualquer plano nacional de enfrentamento da pandemia ou similar (ABRASCO, 2020). Portanto, a pandemia aprofunda um cenário de crise multifatorial brasileira: ela é sanitária, política, econômica, social e humanitária (Observatório de Análise Política em Saúde, 2020).

A COVID-19 exigiu a elaboração de respostas rápidas nos diversos campos sociais, em todo o mundo. (Ferguson et al, 2020). No campo econômico, há preocupação em torno dos efeitos financeiros desta crise sanitária, levando países a 
liberarem verbas específicas para o combate da COVID-19, bem como para proteção de setores de suas economias nacionais, sob forte pressão do mercado (Ewing, 2020). No mundo do trabalho, pesquisa realizada no Reino Unido mostrou o aumento da procura por trabalhos mais precarizados em 2020, sendo que, até o mês de abril, 15\% dos trabalhadores já haviam perdido seus empregos devido à pandemia, majoritariamente jovens e mulheres (Novitz, 2020).

No campo político, especificamente nos parlamentos, foi necessária a conformação de um conjunto considerável de ações, obrigando as casas legislativas e seus agentes a se adaptarem à prática digital. A criação de comissões parlamentares específicas e sessões virtuais tornaram-se comuns, assim como, em paralelo, o surgimento de efeitos advindos da alteração na rotina e comportamento dos membros do parlamento (Griglio, 2020; Koop, 2020; Malloy, 2020; Moulds, 2020).

Foi observada a aprovação em larga escala dos estados de emergência. Através dele, o poder executivo adota medidas extraordinárias, podendo mudar suas funções e a dos demais poderes, conduzindo a disponibilização e alocação de recursos fora do planejado (Ewing, 2020; Petrov, 2020). Esse instrumento foi utilizado por diversos países, a exemplo do Brasil, Reino Unido, Austrália e Canadá, suscitando a discussão sobre democracia, constitucionalidade da medida e o papel de cada um dos três poderes, sobretudo ao olhar minuciosamente a relação entre legislativo e executivo (Addadzi-Koom, 2020; Ewing, 2020; Moulds, 2020; Petrov, 2020).

Alguns estudos revelaram a natureza das leis aprovadas nas casas legislativas, tendo havido diversas medidas de restrição, impulsionadas pela necessidade do distanciamento social na contenção do coronavírus (Ewing, 2020; Moulds, 2020). Em alguns casos, houve preocupação com tais legislações, ao colocar em risco os direitos individuais e aumentar os poderes policiais, por exemplo (Addadzi-Koom, 2020; Ewing, 2020).

Segundo Bourdieu (2014), o Parlamento é entendido como o lugar da política legítima, responsável por formular e regular os conflitos entre os grupos. Sendo assim, como se deu o processo decisório no legislativo baiano frente à situação de pandemia? Quais foram as legislações produzidas para enfrentamento do coronavírus neste campo? Diante do exposto, o presente artigo pretende analisar as respostas legislativas iniciais frente à pandemia da COVID-19, no estado da Bahia, Unidade Federativa do Brasil, no período de março a junho de 2020.

\section{Metodologia}

A política de saúde pode ser entendida como a ação ou omissão do Estado diante das condições e necessidades de saúde dos indivíduos e populações e seus determinantes, assim como em relação a componentes do sistema de saúde, tais como financiamento, gestão, modelo de atenção, organização, cobertura, acessibilidade, qualidade, entre outros, (Paim, 2003; Teixeira \& Paim, 2006). Nesta investigação, foram focalizadas as respostas do Estado, formalizadas pelos agentes do poder legislativo e executivo nos atos legislativos, não tendo sido objeto de análise suas possíveis omissões.

Este trabalho é fruto da dissertação de mestrado intitulada "Formulação de Políticas de Saúde: um olhar sobre o Legislativo baiano entre os anos de 2015 e 2020". Debruça-se sob o conceito do referencial teórico de Pierre Bourdieu sobre campo político, como lócus de estudo, enquanto um microcosmo com autonomia relativa obedecendo às suas próprias leis, no qual disputa-se princípios de visão e divisão do mundo social (Bourdieu, 2011; Vieira da Silva, 2016).

Realizou-se um estudo de caráter exploratório e descritivo, através de pesquisa documental das proposições apresentadas e discutidas na Assembleia Legislativa da Bahia (Alba), bem como das atas das sessões plenárias realizadas. Foram consideradas como proposições legislativas os atos oficiais de autoria dos parlamentares ou poder executivo, com o intuito de criar ou produzir dispositivos regulatórios que alterem leis já em vigor. Dentre essas, listam-se os projetos de lei (PL), as Indicações (IND) e os projetos de decreto legislativo (PDL), relacionados à COVID-19.

Esta pesquisa fez uso de dados secundários, a partir de acesso a informações públicas disponíveis no sítio eletrônico da Alba (https://www.al.ba.gov.br/) e do Diário Oficial do Legislativo (http://egbanet.egba.ba.gov.br/alba). A coleta dos dados 
foi executada em dois momentos: em junho de 2020 e fevereiro de 2021. Optou-se pela realização de uma revisão dos dados coletados, visto que houve atualização no sistema informatizado da Alba ao final do ano legislativo de 2020, tendo acréscimo de processos antes não disponibilizados.

Utilizou-se como argumento de busca a expressão "COVID-19", bem como realizado o cruzamento com as informações contidas em 20 atas das sessões plenárias extraordinárias realizadas entre 23 de março a 01 de junho de 2020, tendo havido 374 respostas de proposições legislativas: 316 PDL e 58 dentre IND e PL. Para fins dessa pesquisa, foram incluídos todos os 316 PDL, todavia descritos na matriz de análise apenas 2 para exemplificação, referentes ao estado da Bahia e à sua capital, Salvador.

O período analisado foi de 01 de março a 01 de junho de 2020, o qual corresponde ao início do surto da COVID-19 no Brasil e antecede ao primeiro pico de casos na Bahia. O sítio citado dispunha de dados e arquivos anexos, os quais continham o processo de tramitação dos atos legislativos, desde a sua entrada, informando sobre autoria, ementa, justificativa, pareceres e tramitação. Esses dados e documentos obtidos foram analisados e sistematizados em planilhas do Microsoft Excel 2007 (https://products.office.com/).

Inicialmente, foram construídas duas matrizes para análise. A primeira organizou as proposições legislativas por data de entrada, ementa, classificação da medida e tramitação. Na segunda, as proposições legislativas foram organizadas pelas variáveis: número da proposição, autor e suas informações pessoais (sexo, data e local de nascimento, partido/bancada, formação, tomada de posição).

Entretanto, determinadas variáveis mostraram-se mais relevantes ao estudo, tendo sido compactadas em uma única matriz de análise (Quadro 1). Em seguida, realizou-se a leitura das 60 proposições legislativas, as quais foram detalhadas e também objeto de análise minuciosa. 
Research, Society and Development, v. 10, n. 16, e367101623585, 2021

(CC BY 4.0) | ISSN 2525-3409 | DOI: http://dx.doi.org/10.33448/rsd-v10i16.23585

Quadro 1 - Distribuição das proposições legislativas segundo data, autor, partido/bancada, medida, tomada de posição e status de tramitação.

\begin{tabular}{|c|c|c|c|c|c|c|}
\hline $\begin{array}{l}\text { DATA DE } \\
\text { ENTRADA }\end{array}$ & $\begin{array}{l}\text { PROPOSIÇÃO } \\
\text { LEGISLATIVA }\end{array}$ & AUTOR & $\begin{array}{l}\text { PARTIDO/ } \\
\text { BANCADA }\end{array}$ & MEDIDA & TOMADA DE POSIÇÃO & STATUS \\
\hline $16 / 03 / 2020$ & IND/24.004/2020 & Júnior Muniz & PP/Maioria & Cancelamento de evento público & Suspensão de eventos públicos e privados & Em tramitação \\
\hline $17 / 03 / 2020$ & IND/24.010/2020 & $\begin{array}{c}\text { Pastor } \\
\text { Isidório Filho }\end{array}$ & AVANTE/Maioria & Investimento de emergência em saúde & $\begin{array}{c}\text { Obras em Hospital estadual para ampliação de leitos } \\
\text { destinados a COVID-19 }\end{array}$ & Em tramitação \\
\hline $19 / 03 / 2020$ & IND/24.014/2020 & $\begin{array}{l}\text { Samuel } \\
\text { Júnior }\end{array}$ & PDT/Maioria & Econômica/fiscal & $\begin{array}{l}\text { Ampliação do prazo para pagamento de tributos estaduais e } \\
\text { municipais }\end{array}$ & Em tramitação \\
\hline $20 / 03 / 2020$ & PDL/2.512/2020 & Nelson Leal & PP/Maioria & $\begin{array}{l}\text { Declaratória de quarentena/ calamidade } \\
\text { pública }\end{array}$ & Reconhece o estado de calamidade pública na Bahia & $\begin{array}{c}\text { Aprovado em } \\
23 / 03 / 2020\end{array}$ \\
\hline $21 / 03 / 2020$ & PDL/2.513/2020* & Nelson Leal & PP/Maioria & $\begin{array}{c}\text { Declaratória de quarentena/ calamidade } \\
\text { pública }\end{array}$ & $\begin{array}{l}\text { Reconhece o estado de calamidade pública no município de } \\
\text { Salvador }\end{array}$ & $\begin{array}{c}\text { Aprovado em } \\
23 / 03 / 2020\end{array}$ \\
\hline $21 / 03 / 2020$ & PL./23.792/2020 & $\begin{array}{l}\text { Defensoria } \\
\text { Pública }\end{array}$ & Não se aplica & $\begin{array}{l}\text { Estabelecimento de orientações/medidas/ } \\
\text { mecanismos de gestão }\end{array}$ & $\begin{array}{l}\text { Adota medidas para proteger a população baiana na vigência } \\
\text { do Plano de Contingência para o Enfrentamento à COVID } 19 \\
\text { da Sesab. }\end{array}$ & Em tramitação \\
\hline 25/03/2020 & IND/24.016/2020 & $\begin{array}{l}\text { Fabiola } \\
\text { Mansur }\end{array}$ & PSB/Maioria & Investimento de emergência em saúde & Implantação de Central de Telemedicina para COVID-19 & Em tramitação \\
\hline $25 / 03 / 2020$ & IND/24.017/2020 & Júnior Muniz & PP/Maioria & $\begin{array}{l}\text { Estabelecimento de orientações/medidas/ } \\
\text { mecanismos de gestão }\end{array}$ & Suspensão da interrupção dos serviços essenciais & Em tramitação \\
\hline $25 / 03 / 2020$ & IND/24.018/2020 & Júnior Muniz & PP/Maioria & $\begin{array}{l}\text { Estabelecimento de orientações/ medidas/ } \\
\text { mecanismos de gestão }\end{array}$ & Suspensão do pagamento de mensalidade escolar & Em tramitação \\
\hline $31 / 03 / 2020$ & PL./23.799/2020 & $\begin{array}{c}\text { Jurailton } \\
\text { Santos }\end{array}$ & REPUB/Minoria & $\begin{array}{l}\text { Estabelecimento de orientações/medidas/ } \\
\text { mecanismos de gestão }\end{array}$ & Redução das mensalidades na rede privada de ensino & Em tramitação \\
\hline $31 / 03 / 2020$ & PL./23.803/2020 & $\begin{array}{l}\text { Jacó Lula da } \\
\text { Silva }\end{array}$ & PT/Maioria & $\begin{array}{l}\text { Estabelecimento de orientações/medidas/ } \\
\text { mecanismos de gestão }\end{array}$ & $\begin{array}{l}\text { Requisição de propriedades privadas para acolhimento de } \\
\text { mulheres vítimas de violência sexista }\end{array}$ & Em tramitação \\
\hline $31 / 03 / 2020$ & PL./23.804/2020 & $\begin{array}{l}\text { Jacó Lula da } \\
\text { Silva }\end{array}$ & PT/Maioria & Econômica/fiscal & $\begin{array}{c}\text { Compra emergencial de produtos oriundos da agricultura } \\
\text { família e/ou dessa natureza }\end{array}$ & Em tramitação \\
\hline $01 / 04 / 2020$ & PL./23.805/2020 & $\begin{array}{l}\text { Talita } \\
\text { Oliveira }\end{array}$ & PSL/Minoria & Gestão e Transparência & $\begin{array}{l}\text { Inclusão do orçamento do combate à pandemia no Portal da } \\
\text { Transparência }\end{array}$ & Em tramitação \\
\hline $02 / 04 / 2020$ & PL./23.806/2020 & $\begin{array}{l}\text { Talita } \\
\text { Oliveira }\end{array}$ & PSL/Minoria & $\begin{array}{l}\text { Estabelecimento de orientações/medidas/ } \\
\text { mecanismos de gestão }\end{array}$ & Suspensão imediata dos prazos de concursos públicos & Em tramitação \\
\hline $02 / 04 / 2020$ & PL./23.808/2020 & $\begin{array}{c}\text { Poder } \\
\text { Executivo* }\end{array}$ & PT/Maioria & Econômica/fiscal & $\begin{array}{l}\text { Pagamento de energia elétrica para consumidores de baixa } \\
\text { renda }\end{array}$ & $\begin{array}{c}\text { Aprovado em } \\
03 / 04 / 2020\end{array}$ \\
\hline
\end{tabular}


Research, Society and Development, v. 10, n. 16, e367101623585, 2021

(CC BY 4.0) | ISSN 2525-3409 | DOI: http://dx.doi.org/10.33448/rsd-v10i16.23585

\begin{tabular}{|c|c|c|c|c|c|c|}
\hline 02/04/2020 & PL./23.809/2020 & $\begin{array}{l}\text { Euclides } \\
\text { Fernandes }\end{array}$ & PDT/Maioria & Econômica/fiscal & $\begin{array}{l}\text { Suspensão da cobrança de pedágio no transporte de cargas } \\
\text { nas rodovias estaduais }\end{array}$ & Em tramitação \\
\hline $02 / 04 / 2020$ & PL./23.811/2020 & $\begin{array}{l}\text { Marcelinho } \\
\text { Veiga }\end{array}$ & PSB/Maioria & $\begin{array}{l}\text { Estabelecimento de orientações/ medidas/ } \\
\text { mecanismos de gestão }\end{array}$ & Internação de pacientes na rede privada de saúde & Em tramitação \\
\hline $02 / 04 / 2020$ & PL./23.812/2020 & $\begin{array}{c}\text { Poder } \\
\text { Executivo* }\end{array}$ & PT/Maioria & Econômica/fiscal & Pagamento de fatura de água para usuários de tarifa social & $\begin{array}{c}\text { Aprovado em } \\
04 / 04 / 2020\end{array}$ \\
\hline $03 / 04 / 2020$ & PL./23.813/2020 & $\begin{array}{c}\text { Poder } \\
\text { Executivo* }\end{array}$ & PT/Maioria & $\begin{array}{c}\text { Estabelecimento de orientações/ medidas/ } \\
\text { mecanismos de gestão }\end{array}$ & $\begin{array}{l}\text { Procedimentos administrativos para aquisição de itens e } \\
\text { contratação de pessoal/ serviços }\end{array}$ & $\begin{array}{c}\text { Aprovado em } \\
04 / 04 / 2020\end{array}$ \\
\hline $08 / 04 / 2020$ & PL./23.819/2020 & $\begin{array}{c}\text { Antônio } \\
\text { Henrique Jr. }\end{array}$ & PP/Maioria & $\begin{array}{c}\text { Estabelecimento de orientações/medidas/ } \\
\text { mecanismos de gestão }\end{array}$ & Suspensão imediata dos prazos de concursos públicos & Em tramitação \\
\hline 08/04/2020 & PL./23.822/2020 & $\begin{array}{l}\text { Jacó Lula da } \\
\text { Silva }\end{array}$ & PT/Maioria & $\begin{array}{c}\text { Estabelecimento de orientações/medidas/ } \\
\text { mecanismos de gestão }\end{array}$ & $\begin{array}{l}\text { Obrigatoriedade de fornecimento de máscaras para } \\
\text { funcionários e clientes de bancos públicos e privados }\end{array}$ & Em tramitação \\
\hline 09/04/2020 & PL./23.827/2020 & $\begin{array}{c}\text { Poder } \\
\text { Executivo* }\end{array}$ & PT/Maioria & $\begin{array}{c}\text { Estabelecimento de orientações/medidas/ } \\
\text { mecanismos de gestão }\end{array}$ & $\begin{array}{l}\text { Obrigatoriedade de uso e fornecimento de máscaras em } \\
\text { estabelecimentos públicos e outros }\end{array}$ & $\begin{array}{c}\text { Aprovado em } \\
11 / 04 / 2020\end{array}$ \\
\hline $13 / 04 / 2020$ & PL./23.828/2020 & $\begin{array}{c}\text { Poder } \\
\text { Executivo* }\end{array}$ & PT/Maioria & Econômica/fiscal & Criação do Vale Alimentação Estudantil & $\begin{array}{c}\text { Aprovado em } \\
14 / 04 / 2020\end{array}$ \\
\hline $16 / 04 / 2020$ & PL./23.842/2020 & $\begin{array}{l}\text { Fabiola } \\
\text { Mansur }\end{array}$ & PSB/Maioria & Econômica/fiscal & Fomento emergencial aos pontos de cultura & Em tramitação \\
\hline $23 / 04 / 2020$ & PL./23.843/2020 & Alex da Piatã & PSD/Maioria & $\begin{array}{c}\text { Estabelecimento de orientações/ medidas/ } \\
\text { mecanismos de gestão }\end{array}$ & $\begin{array}{l}\text { Obrigatoriedade de organização das filas em bancos com } \\
\text { distância mínima de } 1 \mathrm{~m}\end{array}$ & Em tramitação \\
\hline $23 / 04 / 2020$ & PL./23.844/2020 & $\begin{array}{l}\text { Samuel } \\
\text { Júnior }\end{array}$ & PDT/Maioria & $\begin{array}{c}\text { Estabelecimento de orientações/medidas/ } \\
\text { mecanismos de gestão }\end{array}$ & $\begin{array}{l}\text { Horário especial de funcionamento de supermercado e } \\
\text { estabelecimentos similares }\end{array}$ & Em tramitação \\
\hline $23 / 04 / 2020$ & PL./23.845/2020 & $\begin{array}{l}\text { Fabiola } \\
\text { Mansur }\end{array}$ & PSB/Maioria & Econômica/fiscal & Fomento emergencial aos pontos de cultura & Em tramitação \\
\hline $23 / 04 / 2020$ & PL./23.846/2020 & $\begin{array}{l}\text { Roberto } \\
\text { Carlos }\end{array}$ & PDT/Maioria & $\begin{array}{c}\text { Estabelecimento de orientações/medidas/ } \\
\text { mecanismos de gestão }\end{array}$ & Obrigatoriedade do uso de máscaras & Em tramitação \\
\hline $23 / 04 / 2020$ & PL./23.848/2020 & Ivana Bastos & PSD/Maioria & $\begin{array}{c}\text { Estabelecimento de orientações/ medidas/ } \\
\text { mecanismos de gestão }\end{array}$ & $\begin{array}{l}\text { Obrigatoriedade do uso de máscaras no trânsito, local de } \\
\text { trabalho e em circulação externa }\end{array}$ & $\begin{array}{c}\text { Aprovado em } \\
28 / 04 / 2020\end{array}$ \\
\hline $23 / 04 / 2020$ & PL./23.849/2020 & $\begin{array}{l}\text { Roberto } \\
\text { Carlos }\end{array}$ & PDT/Maioria & Econômica/fiscal & $\begin{array}{l}\text { Proibição da cobrança de água, energia elétrica e gás em } \\
\text { alguns estabelecimentos de saúde públicos e filantrópicos }\end{array}$ & Em tramitação \\
\hline $23 / 04 / 2020$ & PL./23.851/2020 & $\begin{array}{l}\text { Eduardo } \\
\text { Alencar }\end{array}$ & PSD/Maioria & $\begin{array}{c}\text { Estabelecimento de orientações/ medidas/ } \\
\text { mecanismos de gestão }\end{array}$ & $\begin{array}{l}\text { Suspensão de obrigações com empréstimos consignados para } \\
\text { servidores públicos }\end{array}$ & Em tramitação \\
\hline $23 / 04 / 2020$ & PL./23.852/2020 & $\begin{array}{l}\text { Diego } \\
\text { Coronel }\end{array}$ & PSD/Maioria & Econômica/fiscal & $\begin{array}{l}\text { Linhas de Crédito e Microcrédito emergencial para } \\
\text { agricultores familiares e afins }\end{array}$ & Em tramitação \\
\hline $29 / 04 / 2020$ & $\mathrm{IND} / 24.160 / 2020$ & Ivana Bastos & PSD/Maioria & Investimento de emergência em saúde & $\begin{array}{l}\text { Instalação de câmaras de descontaminação nas unidades de } \\
\text { saúde }\end{array}$ & Em tramitação \\
\hline
\end{tabular}


Research, Society and Development, v. 10, n. 16, e367101623585, 2021

(CC BY 4.0) | ISSN 2525-3409 | DOI: http://dx.doi.org/10.33448/rsd-v10i16.23585

\begin{tabular}{|c|c|c|c|c|c|c|}
\hline 29/04/2020 & PL./23.856/2020 & Júnior Muniz & PP/Maioria & $\begin{array}{l}\text { Estabelecimento de orientações/medidas/ } \\
\text { mecanismos de gestão }\end{array}$ & $\begin{array}{l}\text { Redução das mensalidade na rede privada de ensino em no } \\
\text { mínimo } 30 \%\end{array}$ & Em tramitação \\
\hline $29 / 04 / 2020$ & PL./23.857/2020 & $\begin{array}{l}\text { Jurandy } \\
\text { Oliveira }\end{array}$ & PP/Maioria & $\begin{array}{l}\text { Estabelecimento de orientações/ medidas/ } \\
\text { mecanismos de gestão }\end{array}$ & $\begin{array}{c}\text { Inclusão do Transtorno do Espectro Autista no rol do grupo } \\
\text { de risco para a Covid-19 }\end{array}$ & Em tramitação \\
\hline $29 / 04 / 2020$ & PL./23.858/2020 & $\begin{array}{l}\text { Jurandy } \\
\text { Oliveira }\end{array}$ & PP/Maioria & Gestão e Transparência & Criação de Central/Fila única de regulação & Em tramitação \\
\hline $29 / 04 / 2020$ & PL./23.859/2020 & $\begin{array}{l}\text { Jurandy } \\
\text { Oliveira }\end{array}$ & PP/Maioria & Gestão e Transparência & Central de informações sobre pacientes internados & Em tramitação \\
\hline $29 / 04 / 2020$ & PL./23.861/2020 & $\begin{array}{l}\text { Euclides } \\
\text { Fernandes }\end{array}$ & PDT/Maioria & $\begin{array}{l}\text { Estabelecimento de orientações/ medidas/ } \\
\text { mecanismos de gestão }\end{array}$ & Ampliação das margens consignáveis para servidores & Em tramitação \\
\hline $29 / 04 / 2020$ & PL./23.862/2020 & $\begin{array}{c}\text { Poder } \\
\text { Executivo* }\end{array}$ & PT/Maioria & $\begin{array}{l}\text { Estabelecimento de orientações/ medidas/ } \\
\text { mecanismos de gestão }\end{array}$ & $\begin{array}{c}\text { Suspensão dos prazos relativos à sanções administrativas e } \\
\text { outras }\end{array}$ & $\begin{array}{c}\text { Aprovado em } \\
14 / 05 / 2020\end{array}$ \\
\hline $05 / 05 / 2020$ & PL./23.864/2020 & $\begin{array}{c}\text { Poder } \\
\text { Executivo* }\end{array}$ & PT/Maioria & $\begin{array}{l}\text { Estabelecimento de orientações/medidas/ } \\
\text { mecanismos de gestão }\end{array}$ & $\begin{array}{c}\text { Sanção a quem divulga fake news em contextos de epidemia, } \\
\text { endemia e pandemia }\end{array}$ & $\begin{array}{c}\text { Aprovado em } \\
22 / 05 / 2020\end{array}$ \\
\hline $06 / 05 / 2020$ & PL./23.865/2020 & Tom Araújo & DEM/Minoria & $\begin{array}{l}\text { Estabelecimento de orientações/medidas/ } \\
\text { mecanismos de gestão }\end{array}$ & $\begin{array}{l}\text { Central de informações sobre pacientes internados e } \\
\text { acolhimento de familiares }\end{array}$ & Em tramitação \\
\hline $06 / 05 / 2020$ & PL./23.867/2020 & $\begin{array}{l}\text { Neusa Lula } \\
\text { Cadore }\end{array}$ & PT/Maioria & $\begin{array}{l}\text { Estabelecimento de orientações/ medidas/ } \\
\text { mecanismos de gestão }\end{array}$ & $\begin{array}{l}\text { Pensão diferenciada para dependentes de servidores falecidos } \\
\text { por COVID-19 }\end{array}$ & Em tramitação \\
\hline $06 / 05 / 2020$ & PL./23.868/2020 & $\begin{array}{c}\text { Talita } \\
\text { Oliveira }\end{array}$ & PSL/Minoria & $\begin{array}{l}\text { Estabelecimento de orientações/ medidas/ } \\
\text { mecanismos de gestão }\end{array}$ & Coleta análise e divulgação de dados epidemiológicos & Em tramitação \\
\hline $06 / 05 / 2020$ & PL./23.870/2020 & $\begin{array}{c}\text { Talita } \\
\text { Oliveira }\end{array}$ & PSL/Minoria & Econômica/fiscal & Plano de auxílio às micro e pequenas empresas e MEI & Em tramitação \\
\hline $06 / 05 / 2020$ & PL./23.873/2020 & $\begin{array}{c}\text { Euclides } \\
\text { Fernandes }\end{array}$ & PDT/Maioria & Campanhas de informação pública & Disparo de informações atualizadas via SMS & Em tramitação \\
\hline $06 / 05 / 2020$ & IND/24.202/2020 & Niltinho & PP/Maioria & Econômica/fiscal & Inclusão dos transportadores escolares em benefício & Em tramitação \\
\hline $06 / 05 / 2020$ & IND/24.203/2020 & Niltinho & PP/Maioria & Econômica/fiscal & Isenção de IPVA aos transportadores escolares em 2020 & Em tramitação \\
\hline $06 / 05 / 2020$ & IND/24.205/2020 & Niltinho & PP/Maioria & Econômica/fiscal & $\begin{array}{l}\text { Contratação dos transportadores escolares para deslocamento } \\
\text { de profissionais de saúde ou equipamentos }\end{array}$ & Em tramitação \\
\hline $07 / 05 / 2020$ & PL./23.874/2020 & $\begin{array}{c}\text { Poder } \\
\text { Executivo* }\end{array}$ & PT/Maioria & Econômica/fiscal & $\begin{array}{l}\text { Auxílio financeiro para internados nos Centros de } \\
\text { Acolhimento }\end{array}$ & $\begin{array}{c}\text { Aprovado em } \\
14 / 05 / 2020\end{array}$ \\
\hline $13 / 05 / 2020$ & PL./23.875/2020 & $\begin{array}{l}\text { Euclides } \\
\text { Fernandes }\end{array}$ & PDT/Maioria & Econômica/fiscal & Suspende a incidência do ITD & Em tramitação \\
\hline $13 / 05 / 2020$ & PL./23.877/2020 & $\begin{array}{l}\text { Euclides } \\
\text { Fernandes }\end{array}$ & PDT/Maioria & $\begin{array}{l}\text { Estabelecimento de orientações/medidas/ } \\
\text { mecanismos de gestão }\end{array}$ & $\begin{array}{c}\text { Registro de ocorrência e medida protetiva de urgência para } \\
\text { mulheres }\end{array}$ & Em tramitação \\
\hline $13 / 05 / 2020$ & PL./23.879/2020 & $\begin{array}{l}\text { Jurandy } \\
\text { Oliveira }\end{array}$ & PP/Maioria & Investimento de emergência em saúde & Ampliação de rede laboratorial diagnóstica & Em tramitação \\
\hline $13 / 05 / 2020$ & PL./23.880/2020 & $\begin{array}{l}\text { Jurandy } \\
\text { Oliveira }\end{array}$ & PP/Maioria & Gestão e Transparência & Criação de Portal de Transparência em todos os municípios & Em tramitação \\
\hline
\end{tabular}


Research, Society and Development, v. 10, n. 16, e367101623585, 2021

(CC BY 4.0) | ISSN 2525-3409 | DOI: http://dx.doi.org/10.33448/rsd-v10i16.23585

\begin{tabular}{|c|c|c|c|c|c|c|}
\hline $13 / 05 / 2020$ & PL./23.882/2020 & $\begin{array}{l}\text { Jurandy } \\
\text { Oliveira }\end{array}$ & PP/Maioria & Investimento de emergência em saúde & Ampliação de rede laboratorial diagnóstica & Em tramitação \\
\hline $20 / 05 / 2020$ & PL./23.887/2020 & $\begin{array}{c}\text { Poder } \\
\text { Executivo* }\end{array}$ & PT/Maioria & Econômica/fiscal & $\begin{array}{l}\text { Institui auxílio temporário aos profissionais que atuam na } \\
\text { linha de frente, na rede estadual de saúde }\end{array}$ & $\begin{array}{c}\text { Aprovado em } \\
22 / 05 / 2020\end{array}$ \\
\hline $21 / 05 / 2020$ & PL./23.890/2020 & $\begin{array}{c}\text { Talita } \\
\text { Oliveira }\end{array}$ & PSL/Minoria & Econômica/fiscal & $\begin{array}{l}\text { Disponibilização de veículo para transporte dos profissionais } \\
\text { essenciais em áreas com circulação proibida/restrita }\end{array}$ & Em tramitação \\
\hline $21 / 05 / 2020$ & PL./23.892/2020 & $\begin{array}{l}\text { Eduardo } \\
\text { Salles }\end{array}$ & PP/Maioria & $\begin{array}{c}\text { Estabelecimento de orientações/ medidas/ } \\
\text { mecanismos de gestão }\end{array}$ & $\begin{array}{c}\text { Instalação de Câmaras de desinfecção em estabelecimentos } \\
\text { diversos }\end{array}$ & Em tramitação \\
\hline $21 / 05 / 2020$ & PL./23.895/2020 & $\begin{array}{l}\text { Olívia } \\
\text { Santana }\end{array}$ & PCdoB/Maioria & Econômica/fiscal & $\begin{array}{c}\text { Criação do Programa Estadual de Transferência de Renda } \\
\text { para mulheres chefes de família }\end{array}$ & Em tramitação \\
\hline $22 / 05 / 2020$ & PL./23.897/2020 & $\begin{array}{c}\text { Poder } \\
\text { Executivo* }\end{array}$ & PT/Maioria & $\begin{array}{l}\text { Estabelecimento de orientações/medidas/ } \\
\text { mecanismos de gestão }\end{array}$ & Altera a celebração de feriados. & $\begin{array}{c}\text { Aprovado em } \\
23 / 05 / 2020\end{array}$ \\
\hline $29 / 05 / 2020$ & PL./23.898/2020 & $\begin{array}{c}\text { Poder } \\
\text { Executivo* }\end{array}$ & PT/Maioria & Econômica/fiscal & $\begin{array}{l}\text { Ajuste comercial e orçamentário para a operacionalização da } \\
\text { Lei do Vale Alimentação Estudantil }\end{array}$ & $\begin{array}{c}\text { Aprovado em } \\
01 / 06 / 2020\end{array}$ \\
\hline
\end{tabular}

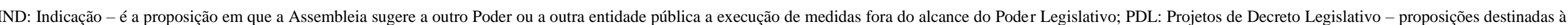

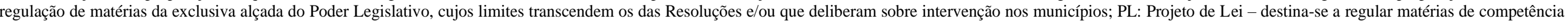
da Assembleia, exercitada com a colaboração do Governador, através de sanção (BAHIA, 2019).

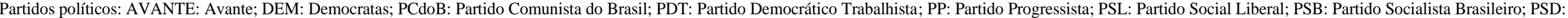
Partido Social Democrático; PT: Partido dos Trabalhadores; REPUB: Republicanos.

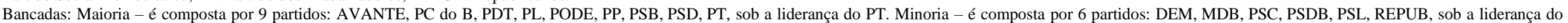
DEM. Há ainda a bancada Independente, integrada pelo PSOL, a qual não figura dentre os agentes políticos deste estudo.

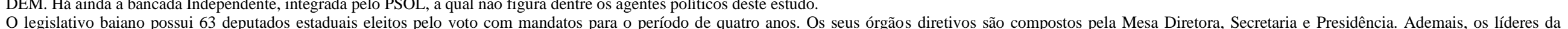
Maioria, Minoria, das bancadas e dos blocos parlamentares constituem o Colégio de Líderes, presidido pelo Presidente da Alba.

Fonte: Elaborado pela autora com base nos dados disponíveis no sítio eletrônico da Alba. 
Na primeira seção, são feitas considerações sobre as mudanças necessárias de adaptação ao ambiente digital. Na segunda seção, investigam-se as respostas à pandemia a partir da produção legislativa neste campo político e seus agentes. Por fïm, sugerem-se ações e instrumentos de contribuição para a melhora desse cenário.

\section{Resultados e Discussão}

O contexto pandêmico imprimiu uma nova dinâmica ao campo político. Na pandemia de COVID-19 há disputa de autoridade e legitimidade na organização de respostas à emergência sanitária, bem como a própria efetividade destas. Para fins deste artigo, analisaremos apenas as respostas legislativas, focadas em seu processo decisório e conteúdo produzido no parlamento.

As adequações do Poder Legislativo à realidade da pandemia foram diversas. Estudo com parlamentos europeus descreveu ao menos 3 respostas repetidamente utilizadas pelos mesmos: a adoção de soluções procedimentais e organizacionais; a responsabilização legislativa por respostas governamentais; e a ativação de mecanismos não legislativos (Griglio, 2020).

Em 23 de março de 2020, doze dias após a declaração de pandemia pela OMS e 17 dias após a observação do primeiro caso de COVID-19 no estado, a Assembleia Legislativa da Bahia realizou a sua primeira sessão plenária extraordinária virtual. Sendo assim, a primeira resposta da Alba à pandemia foi de natureza organizativa. Um conjunto de ações foi instituído, como a adoção de um sistema de deliberação remoto, a diminuição do número de sessões, a supressão das reuniões de Comissão, o fechamento ao público externo, o escalonamento de pessoal, dentre outras. As sessões passaram a se dar exclusivamente em modo virtual, tendo havido 20 delas no período em análise. Dentre essas, apenas 1 não obteve o quórum necessário para instalação.

De acordo com as informações contidas nas atas das citadas sessões, pode-se afirmar que os encontros tiveram funcionalidade. Em que pese o ineditismo da metodologia utilizada, houve unânime adesão e adaptação dos parlamentares à realidade. No conteúdo das oratórias, documentadas por texto, além de áudio e vídeo, citam-se votações e decisões céleres, não tendo havido uso do artifício de obstrução por parte da bancada de oposição.

Sendo assim, algumas importantes características foram observadas, tal qual a aprovação de dispositivos legais para regulamentar o trabalho parlamentar remoto, nível de segurança de ferramentas e uma alta assiduidade dos parlamentares às sessões. O achado de uma casa legislativa que seguiu desenvolvendo suas atividades de forma remota na pandemia confirma resultado de pesquisa realizada com as demais casas subnacionais do país, que classificou a Alba como modelo de gestão digital parlamentar na pandemia (Mitozo, 2020).

As proposições no período foram aprovadas exclusivamente em plenário - à exceção das IND, que são julgadas pela Mesa Diretora - ocorrendo discussão no âmbito das comissões nas próprias sessões, com o uso da dispensa de formalidades regimentais. O plenário constituiu-se como a instância decisória central na aprovação dos projetos de lei ou de decreto legislativo, enquanto as Indicações foram deliberadas pela Mesa Diretora. Esse achado corrobora pesquisa anterior, a qual demonstrou que, para os parlamentares baianos, as instâncias mais importantes do legislativo, pela ordem, são: o plenário, a mesa diretora e as comissões permanentes (Rocha, 2012).

As Comissões tiveram um papel secundário na agenda de trabalhos e resultado legislativo final durante os primeiros meses de pandemia. No período analisado, não foram convocadas reuniões próprias para discussão de projetos ou outras ações. A atuação dessas câmaras esteve restrita às relatorias de projetos e aprovações de proposições em plenário.

Os dados obtidos confirmam o efeito do pedido de urgência e dispensa de formalidades sobre discussão nas 
comissões, esvaziando-as. A atuação do Colégio de Líderes, através do mecanismo da tramitação urgente, mostrou-se decisiva para o funcionamento do legislativo e para a transformação em lei dos projetos aí introduzidos (Figueiredo \& Limongi, 1995).

Do total de 58 proposições descritas no Quadro 1, 86,21\% (50) foram provenientes da Maioria, em contraponto aos 12,07\% (7) da Minoria. A hegemonia da base aliada ao governo na propositura em saúde ratifica estudo anterior (Sobrinho et $a l$, 2018). Os projetos da Minoria propunham, em sua maioria, ementas que versaram sobre transparência na alocação de recursos durante a pandemia pelo estado e municípios, bem como se preocuparam com a reunião e divulgação adequada dos dados epidemiológicos e informações sobre o novo coronavírus.

A bancada da Minoria colaborou de forma significativa e assentiu com as propostas solicitadas e encaminhadas pelo governo. Não houve registro de voto contrário dos membros desta bancada nas proposições sobre COVID-19 analisadas no período. A obstrução da pauta pela Minoria, quando observada nesse período, foi motivada por pautas vindas do Executivo sem relação com a pandemia, não tendo impacto no conjunto da produção legislativa sobre COVID-19.

\section{Produção legislativa}

No período em análise, foram apresentadas 374 proposições legislativas tendo como referência as medidas de enfrentamento à pandemia. Quanto à tipologia normativa, predominaram os Projetos de Decreto Legislativo (PDL), com 316 processos (84,5\%), seguida pelos Projetos de Lei (PL), com 48 (12,8\%), e as Indicações, com 10 (2,7\%), conforme o Gráfico 1.

Gráfico 1 - Proposições legislativas segundo tipologia normativa. Bahia, março a junho de 2020.

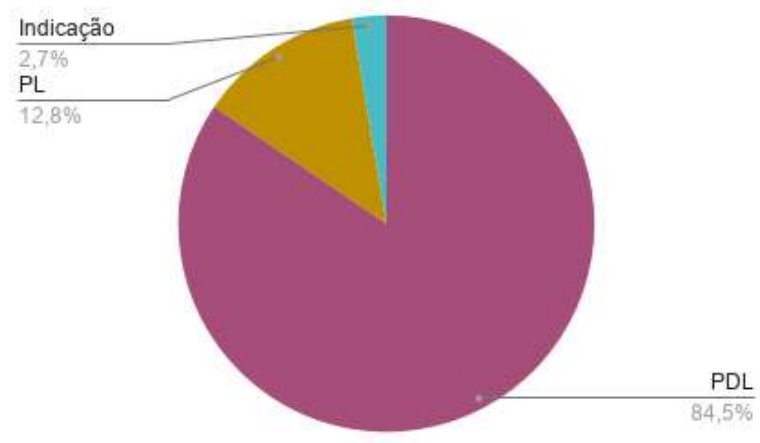

Fonte: Autores, com base em informações obtidas no sítio eletrônico da Alba.

Os PDL são destinados a regular matéria da exclusiva alçada do Poder Legislativo, tendo por objeto, dentre outros assuntos, deliberar sobre a intervenção nos municípios (BAHIA, 2019). No período analisado, os PDL versaram exclusivamente sobre a declaração de calamidade pública. As primeiras duas aprovações com essa finalidade, a do estado da Bahia e sua capital, ocorreram em 23 de março. Até 01 de junho de 2020, 75,54\% dos 417 municípios tiveram este mecanismo aprovado na Alba, sob autoria do/a/s Deputado/a/s com os quais a Prefeitura da cidade mantém relações políticas.

Nesse aspecto, este estudo corrobora achado com pesquisas de outros parlamentos, visto que o dispositivo de governança de emergência tem sido utilizado para acomodação estatal (Ewing, 2020; Moulds, 2020; Addadzi-Koom, 2020; Petrov, 2020). A despeito de decretos legislativos adotados por países como Reino Unido e Austrália, os quais apostam em leis de restrição de circulação para assegurar o isolamento social, não foram verificadas tais ações na Alba (Addadzi-Koom, 2020; Ewing, 2020; Moulds, 2020). Essas medidas, sejam elas da esfera estadual ou de prerrogativa dos municípios, não foram alvo de discussão mais aprofundada na casa, visto que não conformam dúvidas quanto à constitucionalidade ou limites à 
democracia.

As Indicações são proposições através das quais a Assembleia sugere a outro Poder ou a outra entidade pública a execução de medidas (BAHIA, 2019). É uma relação que não há necessariamente efetividade, nem garantias ou obrigatoriedade de atendimento ou resolução. (D’ávila Filho et al., 2011). Pode se configurar numa resposta às bases eleitorais dos parlamentares em suas demandas pontuais, possibilitando-os interferir em demandas de maior volume, a pedido de entidades ou setores organizados. (Torrens, 2018).

Ao contrário das leis ordinárias, o rito de aprovação das Indicações na Alba está concentrado na Mesa Diretora, a qual possui poderes terminativos para estas matérias. As 10 peças identificadas nesta pesquisa foram recepcionadas na Mesa Diretora tão logo apresentadas, conforme extrato de tramitação, embora tenham sido apreciadas por esta instância somente em outubro de 2020, quando $60 \%$ delas foram aprovadas. Para fins deste estudo, o qual investiga as primeiras respostas de enfrentamento à COVID-19, as Indicações terão como status de tramitação "Encaminhado à Mesa Diretora".

Gráfico 2 - Cronologia das medidas aprovadas na Alba versus casos novos confirmados e nº de óbitos por COVID-19. Bahia, março a junho de 2020 .

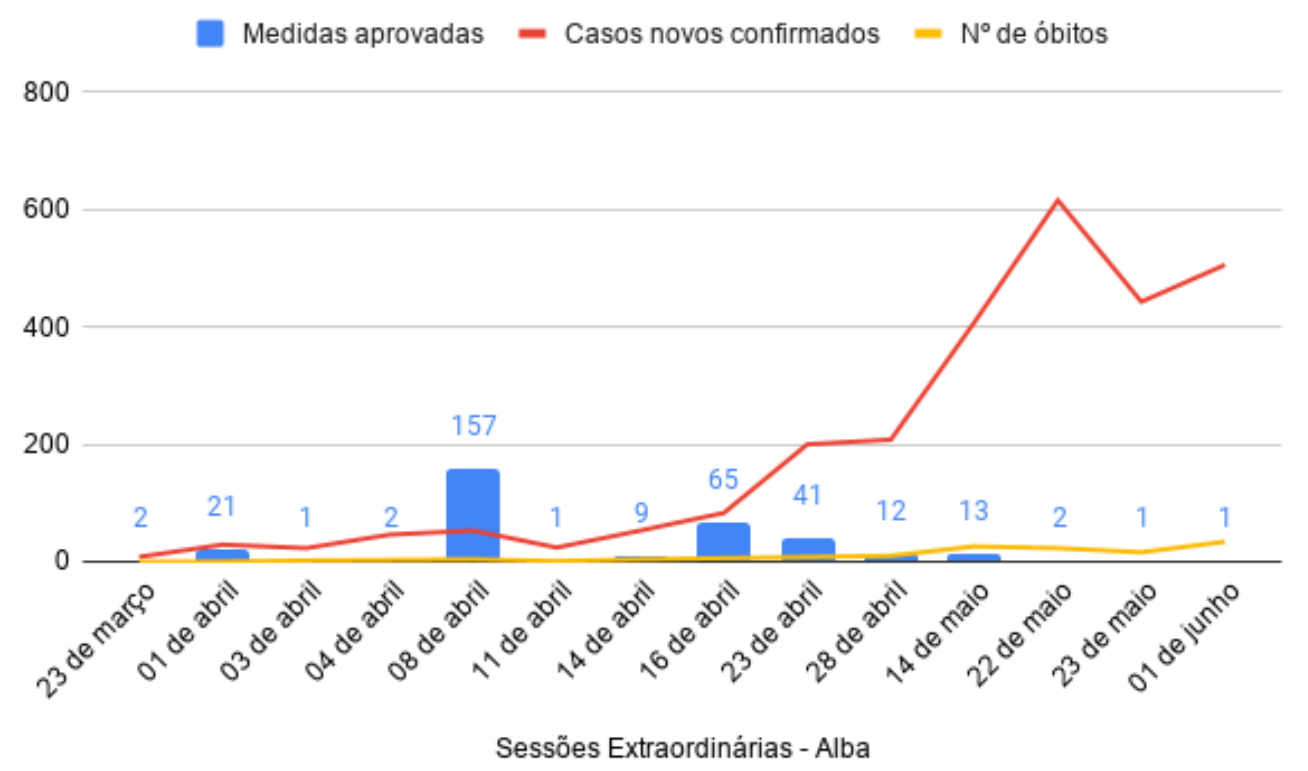

Fonte: Elaborado com base nos dados disponibilizados pela Central Integrada de Comando e Controle da Saúde da Secretaria Estadual de Saúde (https://bi.saude.ba.gov.br/transparencia/em) e em informações obtidas no sítio eletrônico da Alba.

No que se refere à velocidade das medidas adotadas, o Gráfico 2 apresenta a cronologia das proposições aprovadas em cada sessão extraordinária em relação à progressão da doença no estado. No período em análise, foram totalizados 18.843 casos novos confirmados e 697 óbitos por COVID-19. Destes, 67,4\% ocorreu no município de Salvador, capital do estado (BAHIA, 2020).

Como apontado no gráfico, pode-se afirmar que a ampla maioria dos dispositivos legais aprovados no período ocorreu em momento que antecede ao $1^{\circ}$ pico de casos na Bahia, em junho de 2020 (PORTAL G1 a , 2020). Ou seja, houve mobilização dos agentes políticos para conformar arranjos institucionais que possibilitaram a governança no período ou que preparam o estado a partir de orientações e medidas.

Para aprofundamento, as proposições legislativas foram estratificadas conforme a finalidade da medida (Tabela 1). 
Research, Society and Development, v. 10, n. 16, e367101623585, 2021

(CC BY 4.0) | ISSN 2525-3409 | DOI: http://dx.doi.org/10.33448/rsd-v10i16.23585

Tabela 1 - Proposições legislativas segundo finalidade da medida. Bahia, março a junho de 2020.

\begin{tabular}{lcccc}
\hline \multirow{2}{*}{ Medida } & \multicolumn{2}{c}{ Apresentadas } & \multicolumn{2}{c}{ Aprovadas } \\
\cline { 2 - 5 } & $\mathbf{N}$ & $\mathbf{\%}$ & $\mathbf{N}$ & \% \\
\hline Declaratória de calamidade pública & 316 & 84,49 & 316 & 96,34 \\
Estabelecimento de orientação/ medidas/ & 27 & 7,22 & 6 & 1,83 \\
mecanismos de gestão & 20 & 5,35 & 6 & 1,83 \\
Econômica/fiscal & 5 & 1,34 & 0 & 0 \\
Investimento de emergência em Saúde & 4 & 1,07 & 0 & 0 \\
Gestão e Transparência & 1 & 0,27 & 0 & 0 \\
Cancelamento de eventos públicos & 1 & 0,27 & 0 & 0 \\
Campanhas de informação públicas & \multicolumn{1}{c}{ Total } & $\mathbf{3 7 4}$ & $\mathbf{1 0 0}$ & $\mathbf{3 2 8}$ \\
\hline
\end{tabular}

Fonte: Categorias adaptadas do estudo de Hale et al (2020). Elaborado pela autora com base em informações obtidas no sítio eletrônico da Alba.

Das 7 categorias construídas nesta pesquisa, apenas 3 tiveram proposições aprovadas: as declaratórias de calamidade pública, representando 96,34\% dessas; as que estabeleceram orientações/medidas/mecanismos de gestão, com 1,83\%; e as de finalidade econômica/fiscal, com também 1,83\%. Estas proposições sugerem esforço no preparo da atuação da máquina pública para o combate à pandemia, do estado e municípios.

Outrossim, esse achado confirma as medidas tomadas por outros parlamentos, a exemplo do Reino Unido, Austrália e até mesmo Brasil (Ewing, 2020; Ipea, 2020; Moulds, 2020). Entretanto, pode se mostrar insuficiente dadas as possibilidades apresentadas e/ou passíveis de apresentação.

Todos os 316 PDL declaratórios de calamidade pública apresentados foram aprovados. Por ser um estado de grande extensão territorial dividida em centenas de municípios (417), e na ausência de mais proposições que interferisse no volume global, o número absoluto e relativo de declarações de calamidade pública encontrado foi $84,49 \%$ das proposições apresentadas e $96,34 \%$ das proposições aprovadas.

Destaca-se que municípios tiveram seu PDL proposto pelo/s parlamentar/es de sua referência, aquele/s com o/s qual/is há vinculação política e sustentação eleitoral. Ressalta-se que, ao destinar-se a municípios, territórios ou segmentos específicos, as medidas ratificam o seu viés "paroquialista” (D’ávila Filho et al., 2011; Torrens, 2018; Tomio \& Ricci, 2012).

Dentre as proposições não aprovadas, as quais são em sua totalidade de autoria do poder legislativo, algumas chamam a atenção e cabe breve detalhamento. Um exemplo interessante diz respeito à categoria dos transportadores escolares. Gravemente afetada pelo fechamento das unidades escolares, exerceu um conjunto de movimentos públicos pela concessão governamental de benefícios específicos (PORTAL G1 ${ }^{\text {b }}$, 2020). Com isso, um mesmo parlamentar foi autor de 3 propostas distintas com público-alvo nesses trabalhadores: inclusão da categoria em benefício; isenção de IPVA; contratação de trabalhadores para serviços durante a pandemia. Esse tipo de norma denota a relação entre agentes políticos e parte do eleitorado mais organizado, como sindicatos, associações, representações de categorias, grupos de pressão (Tomio \& Ricci, 2012).

Com respeito aos setores sociais mais vulneráveis durante a pandemia, houve iniciativas no que se refere à proteção das mulheres. Segundo dados da Ouvidoria Nacional dos Direitos Humanos (2020), entre os primeiros 25 dias do mês março houve crescimento de 18\% no número de denúncias registradas pelos serviços Disque 100 e Ligue 180 (BRASIL, 2020). Organizações voltadas ao enfrentamento da violência doméstica têm relacionado o aumento da violência doméstica à coexistência forçada com o agressor, ao estresse econômico e aos temores sobre o coronavírus (Vieira et al., 2020). 
Research, Society and Development, v. 10, n. 16, e367101623585, 2021

(CC BY 4.0) | ISSN 2525-3409 | DOI: http://dx.doi.org/10.33448/rsd-v10i16.23585

Artigo de Marques et al. (2020), recomenda o incentivo às iniciativas de apoio às mulheres em situação de violência, durante a pandemia, a partir do acolhimento e aconselhamento psicológico, socioassistencial, jurídico e de saúde. Nesse sentido, os PL 23.877/2020, o qual facilita o registro de ocorrência e o pedido de medida protetiva a partir da Delegacia Digital, e o 28.803/2020, o qual requisita propriedades privadas para acolhimento de mulheres vítimas de violência sexista, se aprovados, contribuiriam para a conformação de cenário de mitigação deste fenômeno social.

A discussão do público versus privado na saúde esteve presente em muitas proposições apresentadas. Medidas para a constituição de uma central única de regulação, com fila única gerida pelo setor público; disponibilização de leitos em unidades privadas; e ampliação de rede conveniada laboratorial ao SUS, caminharam no sentido de reconhecer deficiências e valorizar um sistema de saúde público, universal e gratuito. Paralelamente, o sistema privado saiu de cena enquanto protagonista no imaginário popular neste contexto, dando espaço ao SUS, que atende a todos enquanto direito (Costa et al., 2020). Segundo Fachhini (2020), o coronavírus tornou-se uma oportunidade histórica de resgatar a centralidade do SUS na política social e da Atenção Básica no sistema de saúde brasileiro.

Quadro 2 - Leis de enfrentamento à COVID-19 sancionadas, por ordem cronológica. Bahia, março a junho de 2020.

\begin{tabular}{|c|c|c|c|c|}
\hline Lei & Autoria & PL & Ementa & $\begin{array}{c}\text { Tramitação } \\
\text { (dias) }\end{array}$ \\
\hline $14.255 / 2020$ & $\begin{array}{c}\text { Poder } \\
\text { Executivo }\end{array}$ & $23.808 / 2020$ & $\begin{array}{l}\text { Autoriza o Poder Executivo a destinar recursos para pagamento } \\
\text { das faturas residenciais de energia elétrica de consumidores de } \\
\text { baixa renda que residam no Estado da Bahia, na forma que } \\
\text { indica. }\end{array}$ & 1 \\
\hline $14.256 / 2020$ & $\begin{array}{c}\text { Poder } \\
\text { Executivo }\end{array}$ & $23.812 / 2020$ & $\begin{array}{l}\text { Autoriza ao Poder Executivo a destinar recursos para o } \\
\text { pagamento das faturas residenciais de água de consumidores de } \\
\text { baixa renda beneficiários de tarifa social que residam no } \\
\text { Estado da Bahia, na forma que indica. }\end{array}$ & 2 \\
\hline $14.257 / 2020$ & $\begin{array}{c}\text { Poder } \\
\text { Executivo }\end{array}$ & $23.813 / 2020$ & $\begin{array}{l}\text { Dispõe sobre procedimentos complementares para } \\
\text { enfrentamento da emergência de saúde pública de importância } \\
\text { internacional decorrente do coronavírus e dá outras } \\
\text { providências. }\end{array}$ & 1 \\
\hline $14.258 / 2020$ & $\begin{array}{c}\text { Poder } \\
\text { Executivo }\end{array}$ & $23.827 / 2020$ & $\begin{array}{l}\text { Dispõe sobre a obrigatoriedade de uso e fornecimento de } \\
\text { máscaras em estabelecimentos públicos, industriais, comerciais } \\
\text { e bancários, como medida de enfrentamento à disseminação do } \\
\text { novo coronavírus, causador da COVID-19, na forma que } \\
\text { indica, e dá outras providências. }\end{array}$ & 2 \\
\hline $14.259 / 2020$ & $\begin{array}{c}\text { Poder } \\
\text { Executivo }\end{array}$ & $23.828 / 2020$ & $\begin{array}{l}\text { Cria o Projeto Vale Alimentação Estudantil, destinado a ações } \\
\text { de transferência de renda aos estudantes da rede pública } \\
\text { estadual de ensino, configurando benefício complementar } \\
\text { emergencial, em razão do estado de calamidade pública em } \\
\text { saúde decorrente da pandemia da COVID-19, e dá outras } \\
\text { providências. }\end{array}$ & 1 \\
\hline $14.261 / 2020$ & $\begin{array}{l}\text { Deputada } \\
\text { Ivana } \\
\text { Bastos } \\
\text { (PSD) }\end{array}$ & $23.848 / 2020$ & $\begin{array}{l}\text { Dispõe sobre o uso obrigatório de máscaras pelas pessoas em } \\
\text { circulação externa, bem como em seus locais de trabalho e no } \\
\text { trânsito, nos municípios em que estão em vigor os Decretos } \\
\text { Legislativos de Reconhecimento de Estado de Calamidade } \\
\text { Pública aprovados pela Assembleia Legislativa do Estado da } \\
\text { Bahia, como medida de enfrentamento à propagação e infecção } \\
\text { do Coronavírus, causador da COVID-19, na forma que indica, } \\
\text { e dá outras providências. }\end{array}$ & 5 \\
\hline $14.263 / 2020$ & $\begin{array}{c}\text { Poder } \\
\text { Executivo }\end{array}$ & $23.862 / 2020$ & $\begin{array}{l}\text { Dispõe sobre a suspensão, face à calamidade pública em saúde } \\
\text { decorrente da pandemia da COVID-19, da contagem de prazos } \\
\text { relativos a sanções administrativas, a processos administrativos } \\
\text { disciplinares e sancionatórios que indica, e dá outras } \\
\text { providências. }\end{array}$ & 15 \\
\hline $14.268 / 2020$ & $\begin{array}{c}\text { Poder } \\
\text { Executivo }\end{array}$ & $23.864 / 2020$ & $\begin{array}{l}\text { Estabelece a aplicação de sanção a quem, ilicitamente, divulga } \\
\text { informações falsas sobre epidemias, endemias e pandemias no } \\
\text { Estado da Bahia e dá outras providências. }\end{array}$ & 17 \\
\hline
\end{tabular}


Research, Society and Development, v. 10, n. 16, e367101623585, 2021

(CC BY 4.0) | ISSN 2525-3409 | DOI: http://dx.doi.org/10.33448/rsd-v10i16.23585

\begin{tabular}{|l|c|c|l|c|}
\hline $14.264 / 2020$ & $\begin{array}{c}\text { Poder } \\
\text { Executivo }\end{array}$ & $23.874 / 2020$ & $\begin{array}{l}\text { Autoriza o Poder Executivo a destinar recursos para pagamento } \\
\text { de auxílio financeiro em favor de indivíduos infectados com o } \\
\text { novo coronavírus, que aceitem ser hospedados nos Centro de } \\
\text { Acolhimento e Acompanhamento Clínico do Estado da Bahia, } \\
\text { na forma que indica. }\end{array}$ & 7 \\
\hline $14.266 / 2020$ & $\begin{array}{c}\text { Poder } \\
\text { Executivo }\end{array}$ & $23.887 / 2020$ & $\begin{array}{l}\text { Institui auxílio excepcional e temporário aos profissionais que } \\
\text { atuam na rede pública estadual de saúde no combate ao novo } \\
\text { coronavírus, causador do COVID-19, e dá outras providências. }\end{array}$ & 2 \\
\hline $14.267 / 2020$ & $\begin{array}{c}\text { Poder } \\
\text { Executivo }\end{array}$ & $23.897 / 2020$ & $\begin{array}{l}\text { Altera as datas de celebração dos feriados de Dois de Julho e } \\
\text { São João, na forma que indica. }\end{array}$ & 1 \\
\hline $14.269 / 2020$ & $\begin{array}{c}\text { Poder } \\
\text { Executivo }\end{array}$ & $23.898 / 2020$ & $\begin{array}{l}\text { Altera a Lei } \mathrm{n}^{\circ} 14.259 \text {, de } 14 \text { de abril de 2020, na forma que } \\
\text { indica, e dá outras providências. }\end{array}$ & 3 \\
\hline
\end{tabular}

Nota: Neste quadro, foi incluída apenas a legislação fruto de projetos de lei. Os projetos de decreto legislativo já foram descritos neste estudo e não foram incluídos no quadro síntese acima.

Fonte: Elaborado com base em informações obtidas no sítio eletrônico da Alba.

O Quadro 2 traz uma síntese das leis de enfrentamento à pandemia sancionadas no período. Cinco aspectos mostramse relevantes e serão alvo de descrição adiante: i) o amplo protagonismo do executivo, autor de 91,7\% das leis sancionadas; ii) o tempo célere de tramitação das matérias, tendo média de 4,75 dias; iii) a predileção por políticas de proteção social, com transferência de renda, totalizando $50 \%$ das leis sancionadas; iv) o posicionamento contra as fake news, que possui fortes contornos políticos no Brasil; v) reforço às recomendações da OMS, com a aprovação de Medidas Não Farmacêuticas (MNF) na Bahia.

Em que pese o Congresso Nacional ser objeto de investigações permanentes, há escassez de estudos das casas subnacionais. O achado preliminar neste estudo sugere características similares ao "ultrapresidencialismo estadual", termo cunhado por Abrucio (1998) para caracterizar a força dos governadores, com poder concentrado, legislando assuntos de maior relevância a partir de uma maioria nas assembleias. Neste cenário, haveria "hipertrofia do executivo" e um "papel homologatório" do legislativo.

A definição acima parece encontrar respaldo com os dados até aqui obtidos. Enquanto a dominância do executivo na produção legislativa foi de 22,92\% (dentre os projetos de lei), o seu sucesso legislativo foi de $100 \%$, já que aprovou todas as suas matérias. Do lado oposto, o legislativo apresentou 77,08\% dos PL e aprovou apenas 2,7\% deles.

Todas as votações ocorreram em regime de urgência, com a dispensa das formalidades regimentais. Estudos demonstram que esse mecanismo, liderado pelas lideranças partidárias, têm mais chance de sucesso na aprovação de matérias (Amorim Neto \& Santos, 2002; Ricci, 2003). Ademais, 4 proposições transcorreram em tramitação breve e foram aprovadas em 1 dia. Destaca-se também a necessidade de ações céleres em um cenário de pandemia.

De acordo com Cardozo (2009), a aprovação de matérias em tempo restrito não favorece o debate e respeito à pluralidade, característicos do agir legislativo. Entretanto, parece justificar-se a formulação célere de legislação estadual em tempos pandêmicos. Ainda assim, quais seriam os limites desse legislar em um estado de exceção sanitária? Qual o papel exercido pelo legislativo na resposta à pandemia? Sem a pretensão de elencar respostas, provoca-se a discussão para estímulo a produções científicas futuras.

A pandemia e a crise multifatorial ratificaram a desigualdade no país e trouxeram enormes desafios para as políticas públicas. Primeiramente, há a necessidade de uma efetiva atuação do Estado na preservação da renda, dos empregos e no suporte às populações mais vulneráveis (Arrais et al., 2020). Como exemplo, têm-se as políticas de transferência de renda, intimamente ligadas à estruturação do Estado do Bem Estar Social, assegurando às famílias sobrevivência em um tipo de “segurança protetora" (Sen, 2000).

Dados mostram que 4,32\% dos domicílios brasileiros (cerca de 2,95 milhões) sobreviveram apenas com os 
rendimentos recebidos do Auxílio Emergencial, instituído pela Lei no 13.982/2020, votado pelo Senado em 30 de março. A proporção de domicílios exclusivamente dependentes foi muito maior no Nordeste e, ao todo, $43 \%$ dos brasileiros dizem ter feito o pedido para receber o benefício (IPEA, 2021).

Entre os meses de abril a maio, a Alba aprovou ao menos 5 medidas de transferência de renda indireta focalizadas. Estas se configuram na oferta de serviços públicos e programas emergenciais de auxílio, e tiveram como alvo cidadãos mais vulneráveis e outros segmentos sociais.

Nessa perspectiva, foram aprovadas as Leis 14.255/2020 e 14.256/2020 (ambas do Poder Executivo), as quais isentam o beneficiário de baixa renda do pagamento das faturas residenciais de energia elétrica e água, respectivamente, por um período de 3 meses. No caso da energia elétrica, a isenção estadual foi aprovada 5 dias antes da MP 950/2020 do governo federal, de finalidade equivalente.

Em 14 de abril, a Alba aprovou o Projeto Vale Alimentação Estudantil - PVAE (Lei 14.259/2020). De autoria do Poder Executivo, define-se como concessão de benefício complementar emergencial, disponibilizando o valor de 55 reais para os estudantes da rede pública estadual de ensino, abrangendo mais de 800 mil alunos (BAHIA, 2021).

Outra política focalizada diz respeito à Lei 14.266/2020 (Poder Executivo), que prevê auxílio excepcional e temporário aos profissionais que atuam na rede pública estadual de saúde no combate ao novo coronavírus. De acordo com esta normativa, o benefício será concedido quando a COVID-19 for causa de afastamento das atividades exercidas e de óbito desses profissionais, com diagnóstico realizado pelo Laboratório Central de Saúde Pública Professor Gonçalo Muniz LACEN/BA.

Ademais, importantes MNF foram aprovadas pelo legislativo baiano. NNo contexto de pandemias, tais normativas referem-se à proteção pessoal, distanciamento social, dentre outras (Uchôa \& Uchôa, 2020). Em 11 de abril, a Alba aprovou a Lei 14.258/2020 (Poder Executivo), que dispõe sobre a obrigatoriedade de uso e fornecimento de máscaras em estabelecimentos públicos, industriais, comerciais e bancários. Após 17 dias, houve a aprovação de nova medida similar, a Lei 14.261/2020, que endureceu o regramento, tornando obrigatório o uso de máscaras pelas pessoas em circulação externa, bem como em seus locais de trabalho e no trânsito.

Por fim, dentro do período estudado, foi aprovada em 14 de maio a Lei 14.264/2020 (Poder Executivo), a qual destina recursos para pagamento de auxílio financeiro em favor de indivíduos infectados com o novo coronavírus, que aceitem ser hospedados nos Centro de Acolhimento e Acompanhamento Clínico do Estado da Bahia. Tal medida parece corresponder à interseção classificatória entre MNF e transferência de renda indireta, visto que provê um incentivo financeiro para garantir a norma de distanciamento social àqueles impossibilitados de fazê-lo, por conta da extrema vulnerabilidade.

Outra faceta do ambiente de crise vivenciado no mundo merece prioridade nas ações governamentais, a infodemia (OMS, 2020). Ela é marcada pela profusão de fake news, fenômeno sócio-simbólico global aprofundado pela erosão na crença das instituições na era da internet (Lazer et al., 2018). E, em tempos de pandemia, a Organização das Nações Unidas para a Educação, a Ciência e a Cultura (UNESCO) cunhou o termo “desinfodemia" para definir a nefasta "desinformação básica sobre a doença de COVID-19” (Posetti \& Bontcheva, 2020).

Estudo organizado na Bahia mostrou que houve a promoção de notícias falsas pelo governo federal, as quais alimentaram divergências políticas, bem como a degradação da ação comunicativa do governo, com anúncios oficiais em desacordo com as normas da OMS (BOLETIM OBSERVA COVID, 2021). Nessa difícil conjuntura, fez-se necessária a adoção de medidas pelos governos subnacionais.

Considerando esse quadro, a Alba aprovou a Lei 14.268/2020 (Poder Executivo) em 22 de maio, que prevê a aplicação de multa de 5 a 20 mil reais a quem divulgar informações falsas, sem procedência oficial, sobre epidemias, endemias 
e pandemias na Bahia. A medida, que será alvo de normas complementares disciplinares futuras, ataca emergencial e parcialmente o problema, já que legislação federal similar, o PL 2630/2020, conhecido como Lei das Fake News, ainda encontra-se em tramitação no Congresso Nacional (Brasília, 2021).

\section{Considerações Finais}

O parlamento/legislativo em regime virtual teve como um dos seus efeitos a drástica redução da participação popular, incluindo o distanciamento dos agentes políticos com seu eleitorado. Este fato foi descrito em demais pesquisas, o que denota a importância de serem pensadas estratégias de aproximação do povo às casas legislativas em tempos digitais (Koop, 2020; Malloy, 2020). Ainda que houvesse limitações concretas devido à impossibilidade de frequentar fisicamente a Alba, esforços poderiam ter sido empreendidos para reproduzir encontros digitais com a sociedade civil, a exemplo de audiências públicas ou reuniões de Comissão. Dessa forma, haveria protagonismo do poder público e fortalecimento da democracia representativa, a partir da difusão de diversas opiniões (Griglio, 2020; Malloy, 2020).

A partir das evidências produzidas neste estudo, recomenda-se ao campo político e científico:

- Atualização adequada das informações disponibilizadas no sítio eletrônico da Alba e das demais instituições públicas. É sabida a importância de manter dados fidedignos para consulta de parlamentares, membros do executivo, assessorias técnicas, universidades, entidades e quaisquer pessoas (física ou jurídica), sobretudo nesta era da pós-verdade.

- Fortalecimento das instâncias formais do parlamento, através das quais são discutidas, disputadas e formuladas as políticas públicas, especificamente as Comissões permanentes e temporárias e possíveis frentes parlamentares. Esse movimento consolida valores mais democráticos, contribuindo para a discussão adequada e com participação das vozes dissonantes e o conjunto da sociedade. Inclusive, é possível que a prática digital imposta pela pandemia possa facilitar o fluxo dos processos legislativos, em toda a sua tramitação, bem como a realização de espaços de discussão, ainda que virtuais, como as audiências públicas;

- Monitoramento constante dos legislativos estaduais, em tempos de pandemia ou não. É imprescindível ampliar o arcabouço teórico sobre as casas subnacionais, gerando condições para preenchimento das lacunas observadas no estado da arte, principalmente no que tange às políticas de saúde.

\section{Referências}

Abrucio, F. (1998). Os barões da federação: os governadores e a redemocratização brasileira. Hucitec/Departamento de Ciência Política, USP.

Addadzi-koom, M. E. (2020). Quasi-state of emergency: assessing the constitutionality of Ghana's legislative response to Covid-19. The Theory and Practice of Legislation. https://doi.org/10.1080/20508840.2020.1777648.

Almeida-Filho, N. (2021). Pandemia de COVID-19 no Brasil: equívocos estratégicos induzidos por retórica negacionista. in: CONASS. Principais elementos. Volume 1. https://www.conass.org.br/biblioteca/volume-1-principais-elementos/.

Amorim Neto, O., \& Santos, F. (2002), “A Produção Legislativa do Congresso. Entre a Paróquia e a Nação”, in L. Werneck Vianna (org.), A Democracia e os Três Poderes no Brasil. Belo Horizonte, Editora UFMG.

Arrais, T. A., Oliveira, A. R. de, Alencar, D. P., Salgado, T. R., Viana, J. L., \& Miranda, A. F. (2020). Pandemia covid-19: o caráter emergencial das transferências de renda direta e indireta para a população vulnerável do estado de Goiás. Revista Brasileira de Geografia Econômica. Ano IX. N ${ }^{\circ} 18$. https://doi.org/ 10.4000/espacoeconomia.13734.

Associação Brasileira de Saúde Coletiva (2020). Plano Nacional de Enfrentamento da Pandemia de COVID-19 Abrasco. https://www.abrasco.org.br/site/tag/plano-de-enfrentamento-da-epidemia- de-covid-19/. 
Research, Society and Development, v. 10, n. 16, e367101623585, 2021

(CC BY 4.0) | ISSN 2525-3409 | DOI: http://dx.doi.org/10.33448/rsd-v10i16.23585

Auxílio Emergencial: $1 / 3$ de quem requisitou benefício não recebeu nenhuma parcela, diz Datafolha (2020). O Globo. https://g1.globo.com/economia/noticia/2020/05/28/ auxilio-emergencial-13-de-quem-requisitou-beneficio-nao-recebeu-nenhuma-parcela.ghtml.

Bahia. Assembleia Legislativa da Bahia (2019). Regimento Interno.

https://www.al.ba.gov.br/fserver/:imagensAlbanet:upload:Regimento_Interno_20181.pdf.

Bahia (2020). Central Integrada de Comando e Controle da Saúde da Secretaria Estadual de Saúde. https://bi.saude.ba.gov.br/transparencia/em.

Bahia. (2021) Vale-Alimentação Estudantil será pago nesta sexta-feira. <http://www.bahia.ba.gov.br/2021/05/area-de-imprensa/vale-alimentacao-estudantilsera-pago-nesta-sexta-feira/.

Bourdieu, P (2011). O campo político. Revista Brasileira de Ciência Política; (5):193-216.

Brasil (2020). Coronavírus: sobe o número de ligações para canal de denúncia de violência doméstica na quarentena. https://www.gov.br/mdh/pt-br /assuntos/noticias/2020-2/marco/coronavirus-sobe-o-numero-de-ligacoes-para-canal-de-denuncia-de-violencia-domestica-na-quarentena.

Brasília (2020). Projeto de Lei n 2630, de 2020. https://www25.senado.leg.br/web/atividade/materias/-/materia/141944.

Caponi, S. (2020). Covid-19 no Brasil: entre o negacionismo e a razão neoliberal. Pandemia pela Covid-19. Estud. av. 34 (99). https://doi.org/10.1590/ s01034014.2020.3499.013.

Cardozo, J. E (2009). A crise do Legislativo. Estudos Avançados, 23(67), 79-87. https://www.revistas.usp.br/eav/article/view/10375.

Costa, A. M., Rizzoto, M. L. F., \& Lobato, L. V. C. (2020). Na pandemia da Covid-19, o Brasil enxerga o SUS. EDITORIAL. Saúde debate 44 (125). https://doi.org/10.1590/0103-1104202012500.

D’Ávila Filho, P. M.; Lima, P. C. G. C., \& Jorge, V. L. (2011). Produção legislativa na Câmara Municipal do Rio de Janeiro: indicações, representação política e intermediação de interesses. Desigualdade \& Diversidade - Dossiê Especial, pp. 185-206.

Ewing, K. D. (2020) Covid-19: Government by Decre. King's Law Journal, 31:1, 1-24. https://doi.org/10.1080/09615768.2020.1759398.

Facchini, L. H (2020). COVID-19: Nocaute do neoliberalismo? Será possível fortalecer os princípios históricos do SUS e da APS em meio à pandemia? APS em Revista. ARTIGOS 2(1), 3-10. ESPECIAL COVID-19. ISSN 2596-3317- DOI 10. 14295/aps.v2i1.73.

Ferguson, N. M. et al. (2020). Impact of non-pharmaceutical interventions (NPIs) tore-duce COVID-19 mortality and healthcare demand. https://www.imperial.ac.uk/media/imperial-college/medicine/sph/ide/gida-fellowships/Imperial-College-COVID-19-NPI-modelling-16-03-020.pdf.

Figueiredo, A., \& Limongi, F. (1995). Mudança constitucional, desempenho do Legislativo e consolidação institucional. Revista Brasileira de Ciências Sociais, 10 (29): 175-200.

Griglio, E. (2020). Parliamentary oversight under the Covid-19 emergency: striving against executive dominance. The Theory and Practice of Legislation, https://doi.org/10.1080/20508840.2020.1789935.

Guimarães, R. M. (2018). Os impactos das políticas de austeridade nas condições de saúde dos países com algum tipo de crise. Trab Educ Saúde; 16(1):383385 .

Hale, T., \& Webster, S. (2020). Oxford COVID-19 Government Response Tracker. Data use policy: Creative Commons Attribution CC BY standard.

IPEA - Instituto de Pesquisa Econômica Aplicada (2020). Nota técnica no 31: Instrumentos de políticas públicas para o enfrentamento do vírus da COVID19: uma análise dos normativos produzidos pelo executivo federal. Brasília: Ipea.

IPEA - Instituto de Pesquisa Econômica Aplicada (2021). Carta de Conjuntura ${ }^{\circ}$ 50: Os efeitos da pandemia sobre os rendimentos do trabalho e o impacto do auxílio emergencial: os resultados dos microdados da PNAD Covid-19 de novembro. Brasília: Ipea.

Koop, R., Blidook, K., \& Fuga, L. A. (2020). Has the COVID-19 Pandemic Affected MPs'Representational Activities? Canadian Journal of Political Science 53, 287-291. https://doi.org/10.1017/S0008423920000566.

Lazer

Malloy, J. (2020). The Adaptation of Parliament's Multiple Roles to COVID-19. Canadian Journal of Political Science, 53, 305-309 doi: $10.1017 /$ S0008423920000426.

Moraes, F. (2001). Executivo e Legislativo no Brasil pós Constituinte. Perspect; 15:45-52.

Moulds, S. (2020). Scrutinising COVID-19 laws: An early glimpse into the scrutiny work of federal parliamentary committees. Alternative Law Journal 0(0) 1-8 DOI: 10.1177/1037969X20946990 journals.sagepub.com/home/altlj.

Mitozo, I. B. (2020). A utilização de sistemas deliberativos remotos pelas assembleias legislativas brasileiras durante a pandemia de COVID-19: características e prospectos. Rev. Leg. Pr.Curitiba. (4). 9-24.

Novitz, T. (2020). COVID-19 and Labour Law: United Kingdom. Italian Labour Law e-Journal. 13. https://doi.org/10.6092/issn.1561-8048/10808. Jun. 2020.

Observa COVID. (2021). Análise de Modelos e estratégias de vigilância em saúde da pandemia da COVID-19 (2020-2022). [Fake News na pandemia de COVID-19: respostas governamentais]. Boletim Ano 2. Edição 7. 
Research, Society and Development, v. 10, n. 16, e367101623585, 2021

(CC BY 4.0) | ISSN 2525-3409 | DOI: http://dx.doi.org/10.33448/rsd-v10i16.23585

Observatório De Análise Política Em Saúde. (2020). [Covid-19: distanciamento social, aumento de casos e enfrentamento]. Boletim Ano 6. Edição 28.

PAHO - Pan American Health Organization. (2021). https://www.paho.org/pt/brasil.

Paim, J. S. (2003). Modelos de atenção e vigilância da saúde. In: ROUQUAYROL, M. Z.; ALMEIDA FILHO, N. Epidemiologia \& saúde. MEDSI, 567- 586.

Paim, J. S., \& Teixeira, C. F. (2019). Política, Planejamento e gestão em Saúde: balanço do estado da arte. Rev. Saude Publica 2006; 40, 73-78. https://www.ufrgs.br/napead/repositorio/objetos/edital19/gestaopoliticas/ARQUIVOS\%20PDF/O\%20estado\%20da\%20arte\%20de\%20PP\%20\%20G.pdf.

Petrov, J. (2020). The COVID-19 emergency in the age of executive aggrandizement: what role for legislative and judicial checks? The Theory and Practice of Legislation, https://doi.org/10.1080/20508840.2020.1788232.

Posetti, J., \& Bontcheva, K. (2020). Desinfodemia: Decifrar a informação sobre COVID-19. Resumo de Políticas. UNESCO. https://en.unesco.org/sites/default/files/disinfodemic_deciphering_covid19_disinformation.pdf.

Rocha, M. M. (2012). Comissões parlamentares nos legislativos estaduais brasileiros: estudo das Assembleias Legislativas da Bahia e de Minas Gerais. Cadernos da Escola do Legislativo, Belo Horizonte: Assembleia Legislativa do Estado de Minas Gerais, v. 13, n. 21, p. 139-175.

Ricci, P. (2003). O Conteúdo da Produção Legislativa Brasileira: Leis Nacionais ou Políticas Paroquiais? Dados. Revista de Ciências Sociais, Rio de Janeiro, Vol. 46, no 4, p. 699-734. Disponível em: <https://www.scielo.br/j/dados/a/XvdskMJt4Zyh6BTZpRRXFnd/ ?lang=pt\&format=pdf>.

Sobrinho, J. E. L., Neto, J. I. J., Nascimento, V. H. F., Martelli, P. J. L., \& Lorena, S. B. (2018). Análise das iniciativas do Poder Legislativo estadual de Pernambuco para o setor saúde. Saúde debate; 42(117): 481-488.

Souza, M. C. de, \& Souza, J. N. (2020). Access, Care, Social Inequalities and The Pandemic COVID 19 In Brazil. Biomed J Sci \& Tech Res, 31(4), 243272432. DOI: 10.26717/BJSTR.2020.31.005125.

Sen, A. (2000). Desenvolvimento como liberdade. Cia das Letras.

Tomio, F. R. L., \& Ricci, P. (2012). O governo estadual na experiência política brasileira: os desempenhos legislativos das assembléias estaduais. Rev. Sociol. Polít., 21(41), 193-217.

Torrens, A. C. (2018). A atividade legislativa municipal e sua efetividade. Rev. NEP UFPR. 4(1), 128-163. http://dx.doi.org/10.5380/nep.v4i1

Uchôa, S. B. B., \& Uchôa, B. B. (2020). Coronavírus (Covid-19): um exame constitucional e ético das medidas previstas na lei n. 13.979, de 6 de fevereiro de 2020. Cadernos de Prospeç̧ão UFBA. 13(2). https://periodicos.ufba.br/index.php/nit/article/ view/36163/20967.

Vieira, P. R., Garcia, L. P., \& Maciel, E. L. N. (2020). Isolamento social e o aumento da violência doméstica: o que isso nos revela? Rev Bras Epidemiol; 23: E200033. https://www.scielo.br/j/rbepid/a/tqcyvQhqQyjtQM3hXRywsTn/?format=pdf\&lang=pt.

Vieira da Silva, L. M., Chaves, S. C. L., Esperidião, M. A., Barros, S. G., \& Souza, J. C. (2016). Análise sócio-histórica das políticas de saúde: algumas questões metodológicas da abordagem bourdiesiana. In. Teixeira, C.F. Observatório de análise política em saúde. Salvador: EDUFBA.

WHO - World Health Organization. (2021). https://www.who.int/ eportuguese/countries/bra/pt/. 